\title{
Organizational Mechanisms and Practice of Innovative Talents Cultivation in Local Colleges-A Case Study of Hubei University
}

\author{
Xin $\mathrm{Hu}^{1}$, Hong Wan ${ }^{2}$, Dejin Yang ${ }^{2} \&$ Xi Shen ${ }^{1}$ \\ ${ }^{1}$ Faculty of education, Hubei University, Wuhan, China \\ ${ }^{2}$ Chu Cai college, Hubei University, Wuhai, China \\ Correspondence: Xi shen, Faculty of education, Hubei University, Wuhan, China. Tel: 1-804-054-8669. E-mail: \\ huxin213@sina.com
}

Received: January 10, 2018

Accepted: February 5, $2018 \quad$ Online Published: February 23, 2018

doi:10.5539/hes.v8n1p65

URL: https://doi.org/10.5539/hes.v8n1p65

\begin{abstract}
The organizational mechanisms of innovative talents cultivation in Hubei University are as follows. Firstly, make top-level design on organizational administration such as improving the organization structure, setting up a committee of teaching instruction, establishing the mechanism of coordinative cultivation. Secondly, carry out a series of management system mainly contain teacher system, tutor system, credit system, and semester system. Thirdly, cultivate innovative talents by ways of cultural activities. The effective experiences on cultivating innovative talents in Hubei University mainly includes: improve the enrolment mechanism, "stage-module-personalization" cultivation model, individualized professional education based on liberal education, tutors leading function in academic guidance.
\end{abstract}

Keywords: higher education institutions, innovative talents cultivation, organize, mechanism, practice

\section{Introduction}

Actualizing the strategies, which are the strategy of prospering the nation with science and education and the Strategy of Strengthening Country on Talents all around is the decision-making of Chinese communisty party in new century. Cultivation of innovative talents in colleges and universities has been highly emphasized by our government. And we can easily find bulk of relevant discussions among the mass media. Deepening education reforms and exploring the cultivation of innovative talents play an important role to the development of colleges and universities in China. Moreover, Research by Liu Pengzhi,, Zhou Jianhua and Zhang Jianlin (2013) supports that innovative talents cultivation is the common and differentiated responsibility of universities, primary and secondary schools (Chu Cai College, 2018). Chu Cai college, founded in 2008, is a pilot school of Reform on Undergraduate Innovative Talents Training Mode in Hubei University. After several years of construction and development, a series of explorations were made in the organizational management and system construction of innovative talents training, which ensured the quality of personnel training.

\section{Organization Design}

Making top-level design on organizational administration is the guarantee to implemente reform of talent cultivation mode with better effects achieved. The Chu Cai college has improved the organizational structure of innovative personnel training, set up a committee of teaching instruction, and established the mechanism of coordinative cultivation, within and outside the school.

\subsection{Organizational Structure}

The staffing (Chu Cai college) involves a dean wearing two hats: one as the vice-president for the teaching in Hubei University, the other as dean of Chu Cai college, an executive vice-dean, a vice-dean who is conscientious of the teaching and a deputy Secretary who is put into the charge of students' work. A comprehensive office, a teaching management office, a student work and a youth league office are set up. The staff of every bureaux involves an office administrator, a full-time teaching secretary and an instructors devoted to the students work. (Chu Cai College, 2018)

\subsection{Setting up A Committee of Teaching Instruction}

The members of the Teaching Steering Committee are composed of experts and professors from the Academic 
Administration Office and 9 disciplinary colleges, including business school, Foreign Language Institute, liberal arts college, faculty of education, School of mathematics and computer science, etc. The chairman is the vice-president for academic affairs, Hubei University. The meeting of Committee was held regularly. To better realize the cultivation of innovative talents so that the following work is often discussed, including the discussion on the development of colleges and universities, the problem of training characteristics and target orientation, formulation of talents training scheme, excellent professional tutors selection and other work, at the meeting.

\subsection{Establishing the Mechanism of Coordinative Cultivation}

Collaborative innovation is a necessary path for the cultivation of innovative talents in Colleges and universities. Building the resource sharing mechanism and collaborative education system (Chu Cai College, 2018; Qiu Xueqing \& Li Zheng, 2013), is beneficial to undamentally improve the quality of teaching and education in universities and to achieve the cultivation of innovative talents.

\subsubsection{Support from Various Departments}

Actively support, Originated from the departments of school educational administration, finance, personnel, recruitment and others, has been given in the aspects of teaching arrangement, school management, each allocation and incentive funds, enrollment and so on. And the bold practice has been adopted in the segment of training mode, teaching reform, the credit system, Cultivation of Individualization and others by Chu Cai college. Not only the support but also bold practice have achieved remarkable results. (Liu \& Shen, 2014; Qing Mingju, 2015)

\subsubsection{College Identity}

The system, classified the science and art classes, is carried out by Chu Cai college. Students of Chu Cai college are involved in many colleges and dozens of major in the school. Without the exclusive teachers, the professional collage of excellent teachers and high-quality resources are needed. Given the current issue ,the relevant measures have been taken and the relevant plans and rules have been made in Hubei University. The following measures have been adopted. Firstly, improving the Course grants of the employed teachersa, taking the rewarding and incentive measures. Otherwise, the students' achievements were shared by Chu Cai collegeand theirs professional collage. Simultaneously, in order to benefit more students from the reform measures, the interaction with the professional colleges is increased.With the help of the school, the works of the pilot reform, which was involved by professional collage, were considered as assessment conten of the year-end performance.

\subsubsection{Social Participation}

The training of innovative talents has obtained a comprehensive social support in Hubei University and it was aslo actively involved in social activities. For instance, Chu Cai institute actively sought the peers support to strengthen the dual culture so that students could get the second campus learning experience. Then, it provided funding to encourage students to study in colleges and universities at home and abroad and to take characteristic courses. Meanwhile, it demanded students to serve the society and have a hand in social practice with the knowledge that theirs have acquired. Furthermore, social Masters and famous teachers or masters were invited to the school to organize the students to participate in the activities and embed in enterprise and institution, in order to broaden the students' vision and enrich theirs experience.

\section{Management System}

As a pilot school to cultivate innovative talents, Chu college effectively implemented a series of management system which is different from other professional school. it implemented the pilot, explored the new road of the target, which mainly contain teacher system, tutor system, credit system, and semester system. (Liu et al., 2013, Retrieved from http://ccxy.hubu.edu.cn/xygk/xyjj.htm)

\subsection{Teacher System}

The management methods of teacher recruitment in Chu Cai college of Hubei University(trial), has been formulated to clarify these problems, including the qualifications, procedures, responsibilities and salary allowance standards of teachers. In the second place, we should make full use of high-quality resources in schools, including the distinguished teachers, the award-winners of teaching competitions, the excellent teachers in teaching evaluation, and the distinguished professors and scholars in various disciplines. Then,the policy of special management and special remuneration allowance is implemented. In addition, the college regularly organizes and selects instructors to attend academic meetings and curriculum training.

\subsection{Tutor System}

The following three things are done to ensure the cultivation of innovative talents. Foremost, tutor group of 
freshmen was set up. Its purpose is to help freshmen quickly adapt to the life and studies in university, clarify academic direction, correct learning attitude, set up ambitious ideals and devolop good academic atmospheres. The system is implemented to request the tutors of freshmen to regularly work. Specific methods are as follows: Firstly, tutor studio was established, and a schedule that provides guidance for time arrangements was set up. Then, according to the difference between the students' professional interest and the research direction of the tutor, Chu Cai college sets up a number of groups that involves teachers and students. Meanwhile, it is relatively fixed which include the guidance time, location and object. More than anything, all two forms are accepted. One is the form that a mentor who is only associated with the students in this group, and the other is that a tutor who can be consulted by students outside the groups.

Secondly, the management methods of professional tutors was revised. The management methods of tutor recruitment in Chu Cai college of Hubei University (trial), which was promulgated in 2011, has been revised.The new management methods further clarified the responsibilities of professional tutors, adjusted the workload calculation method of professional tutor, and raised the level of remuneration. Finally, the selection method of excellent professional tutors in Chu Cai College of Hubei University (Trial) was published. The excellent tutors' commendation conference was held every two years, in order to establish outstanding tutors' demonstration and guidance mechanism.

\subsection{Credit System}

The teacher guides the students to choose the courses freely within the framework of teaching plan for the training of innovative talents. Students who want to graduate and get a bachelor's degree must complete the required credits. And they are required to complete their studies, including basic courses, general education courses and related professional courses. After completing the public basic courses, general education courses and related professional courses, students can complete their credits and complete their bachelor's degree. The students are educated for 3-6 years in Chu Cai college. The curriculum of public and general education are arranged by schools. And a few general courses are selected as elective courses, which are closely related to the First Grade Disciplines or major of students. When the credits have been completed in advance, students can graduate or enter postgraduate learning stage in advance. (Qin, 2015; Liu Jie \& Shen Xi, 2014) It encourages students to earn credits by studying in other well-known colleges and universities at home and abroad. Students who entered the University in 2011 were asked to get no less than 140 curriculum credits and 20 credits in the practical teaching.

\subsection{Semester System}

All students are required to take part in these semester that also give academic credits. First of all, Some special courses have been opened for freshmen. The main purpose is to improve theirs comprehensive quality and enhance theirs ability to speak and write in English. Otherwise, the Chu Cai college organized the sophomores to carry out social investigation activities. They are required to declare the topic in advance. When it is examined through the college, the students are given funding and the graduation credits. Finally, the activity which is studying or travelling out of school and the social practices activities in summer vacation were developed. It mainly requires the sophomores and junior students to participate in these activities, including stduies of short-Semester in the famous universities, the academic summer camp and the professional practice.

\section{Cultural Mechanism}

Research by Zhu Yongkun (2016)holds that all favorable educating factors in the school can be used as the content of cultural education (Qiu \& Li, 2013). Cultural education refers to creating educational situations through various activities, implanting and cultivating students in an imperceptible way, so as to cultivate students' ability that consciously transform their learning knowledge into their own behavior and habits.Chu Cai college follows the guidance of "scientific theory to guide students, advanced culture to edify students, excellent models to inspire students, practices experience to cultivate students', designs and carries out cultural activities, and creates a good educational environment.

\subsection{To Guide Ideological and Political Education with Party Building Activities}

The student Party branch launched the "I speak Party lectures" special activities, elected the best speakers from the student party members as obligation speaker of activist training and Party Constitution learning group .

\subsection{Guiding Students to Study Independently by Reading Activities}

There are mainly two activities which are the "book with life"and the" reading the classics, appreciating the cultural". The activity of "book with life" strengthens the students' learning consciousness through teachers' recommendation, independent reading and reading report and others. The activity of "reading classics, 
appreciating the cultural "guides students to use their holidays to study classic books and write their reading experience so as to enhance the learning interest. Through reading activity guidance, students' consciousness of independent cooperation greatly enhanced. Students who major in literature, history and Philosophy spontaneously formed a learning community named "heaven", regularly developed learning and research activities, invited relevant professional teachers together to discuss academic issues, collected and edited their study and research results.

\subsection{To Cultivate Students' Innovative Ability by Scientific Research}

On the one hand, the school encourages students to follow their tutors early into the laboratory and research group, and on the other hand, it invests funds to support students building theirs innovative team and scientific research projects. In 2015, 33 scientific research projects were established by the college, with more than 110 thousand funds. The result is that scientific research activities have promoted the improvement of students' creative ability. In 2015, the college students published more than 40 academic papers, many of which were cited in SCI, 3 people (5 people in the school) were awarded top notch innovative talents scholarships, more than 30 were awarded research and innovation scholarships, and one were awarded the National College Students' "Challenge Cup" extracurricular academic competition silver award.

\subsection{To Promote the Unity of Students' Learning and Doing by Social Practice}

Each year, sophomore students are organized uniformity to develop the summer social survey. In the past 5 years, more than 50 practice teams have organized to conduct social surveys around social hot-spots and professional subjects, which greatly promoted the improvement of students' practical ability. In 2013, The investigation report of "Wuhan citizen's reading status" made by a student team at Chu Cai college, got the title of university student summer social practice excellent team in Hubei province, and it was reported with full page by the"Wuhan Evening News", caused widespread attention in the society.

\subsection{To Strengthen Students Self Education by 'Student Forum'}

The Chu Cai college and the Faculty of education have launched a student forum named "Jiao Yuan Chu Cai", and the undergraduates are the main speakers of the forum. The forum combined with social practice, the scientific research innovation, Selecting and setting up a typical model and other activities are arranged the columns of outstanding students deeds, practical achievement and reading achievement. Let students as models or examples and Students who have experiences and gains of learning, practice, and scientific research to give a lecture in the Forum. It will encourage other students to study diligently by the motivating role of the example around them, and form a learning style of mutual comparison, mutual learning, mutual catching, helping and super. Since 2011, the "Jiao Yuan Chu Cai" forum has been carried out every month.

\subsection{To Improve Students' Comprehensive Quality by Stylistic Activities}

The Chu Cai college encourages students to organize recreational activities autonomously, and gradually forms a stylistic activity system featuring "Chu Cai impression" art performance, "Midsummer Night" drama performance, "3VS3" dormitory basketball game and interesting sports meeting. These activities not only enrich the students' amateur life, but also enhance the cohesiveness of the college.

\section{Practical Exploration}

\subsection{The Enrolment Mechanism}

The Chu Cai college has expended enormous efforts in exploring the enrolment mechanism of innovative talents cultivation. According to the college entrance examination scores, college selects the best students to admit in advance, and makes second selections at the end of the first school year in 2011. In 2012 ,some students were selected after they enter university. A year later, the policies of moderate elimination and diversion were implemented and the other students were added by the recommendation of the professional college. Students who entered Chu Cai college in 2013 were admitted by the method, combining recruitment according to the college entrance examination scores with selection after they enter university. Freshmen are only selected from the professional college to enter the Chu Cai college in 2014.

At present, a set of scientific and effective enrolment procedure has been formed. The main advantages are shown in the following aspects: firstly, the selection time is more reasonable. It was highly valued which are the students' academic achievement, school performance and learning ability when they are recommended as candidate to add into Chu Cai college at the end of first year. Secondly, the way to sign up is now much more diverse than ever before. Students can sign up by three ways in which are self recommendation, expert recommendation, and college recommendation. Meanwhile, the methods of assessment are varied. Students must 
participate in a comprehensive interview and written examination, such as psychological tests, structured interviews, non leadership group discussions, and other evaluation. The purpose of these tests is to assess the students' comprehensive quality, professional interest, scientific research potential, development potential and so on. Above all, the elimination mechanism is implemented A few students who do not conform to the requirements or do not adapt to the training model of the experimental class will be transferred from the experimental class to the corresponding professional classes so that the quality of all students will be guaranteed in Chu Cai college.

\subsection{Talent Cultivation Model}

"stage-module-personalization" cultivation model is adopted to develop individualized professional education on the basis of general education. The "stage" refers to building a staged personnel training programme in order that individualized professional education based on general education is implemented. And the "module" refers to setting up a modular curriculum system with complete educational function and flexible structure. The "personalization" means that the training programs for students vary from person to person, and the training plan for the professional education stage is based on the opinions of the students and tutors.

The two subsections of "1.5+2.5" and "1+3" have been tried. First of all, the college has actively explored the "1.5+2.5" mode. In the first 3 semesters, we focus on general education, and students study 1-2 professional courses per semester which are chose by themselves per semester, so as to clarify their professional intentions gradually. From the fourth semester, students will enter the professional learning stage, and the professional tutors will play a leading role in the implementation of personalized professional education. The second pattern that is explored is the "1+3" model. Relying on the general education college, we carried out a one year general education for the Chu Cai college preparatory students, while some of extra general courses is offered by Chu Cai college. In the four years, professional education is always developed with the general education. At the end of the freshman year, Chu's college assesses the students and diverts their specialties, and formally determines the candidates for the training of innovative talents. The students' personal interests, aspirations, and special abilities are used to guide the students to determine their specialties and to be equipped with professional tutors to carry out individualized professional education.

\subsection{Academic Guidance}

In order to promote the overall development of the students, the academic guidance mechanism is that all personnel extensively participate in the whole process is implemented, and in which the tutors play a leading role.

\subsubsection{The Whole-Process Guidance}

That is, the tutors excavated the personality of the freshmen and made individualized guidance.

First off, in the first year, we should be paid attention to these issues that is freshmen adaption question, Setting up the learning goal, planning the direction of academic development, guidance of the professional ideas and exploring the suitable learning methods, etc. The college has set up a special "tutor studio", the tutors have a fixed duty time, and students can also make an occasionally appointment with tutors. A variety of forms such as individual guidance and collective guidance, face-to-face communication and telephone or network interaction are taken. Otherwise, in order to achieve better personalization cultivation, every sophomore is equipped with a professional tutor. The differences of professional characteristics, students' personality and specialty are considered so that tutors can guide students to learn flexibly and autonomously. Students can study courses across grades, disciplines, colleges, and cross schools, and participate in scientific and technological practical activities with the guidance of tutors. In the third year, professional skills training was strengthen and students was guided to do research. It is means that students are asked to "enter the laboratory, participated project, jion the team", and publish scientific research papers, etc. We pay high attention cultivate the junior students' practical innovation ability. Above all, we focus on Senior students' professional practice, graduation thesis, postgraduate interview, career development planning and so on during their last year.

\subsubsection{Full Member Guidance}

The situation in which all people are involved in guidance is diverse,including experts and students' "face-to-face" communication, famous teachers and leaders enter the class, the two - room decentralized guidance and other forms.

1) Entering the class. For instance, the vice-president of Hubei University who wears another hat as a dean had an informal discussion with students who entered the Chu Cai college in 2013 or 2014. From the school to the college, from discipline to specialty, he introduced school development, discipline construction and faculty 
strength to students, and put forward high requirements for students.

2) Professional navigation. The dean who is in charge of the teaching work from the professional college was invited to develop the major's navigation, mainly introducing the general situation and development prospects, and interacting with the students.

3) Special lecture or seminars. Famous teachers, experts, and outstanding alumni are invited to give lectures. Students are encouraged to do research study, active practice and technological innovation. In order to enable students intuitively feel on the application of high technology in the industry, the college organized students to visit and study in Wuhan cigarette factory, organized students to visit the production workshop ,and the Alumni as senior executives are invited to give special reports. Recently graduates Zheng Di was invited to give a lecture for Chu college students and encourage them to do scientific research. (Zhu, 2016, Retrieved from http://ccxy.hubu.edu.cn/info/1006/3624.htm)

4) To conduct learning guidance in teaching and daily management. The staff from teaching office and the students' work office in the college are required to do well in the management and service, are consulted by students to provide the learning, life, and psychological guidance, answered questions for the students, and are asked to do well in the system of study style management, academic warning, and so on.The class teachers, the tutors and the teaching secretaries cooperate closely in order to get the students' dynamic information in time.

\subsubsection{Omni-Directional Guidance}

It covers all aspects of students' Ideological and moral character, subject specialty, scientific research innovation, promotion and employment, mental health and so on.

1) Guidance of moral character. The Chu Cai college concerned with the growth of the students, helped the students to set up a great ideal and motivated the students to become successful. These guidance help students to understand and adapt to the model of innovative talents cultivation, to understand themselves correctly, and to scientifically formulate learning and life planning.

2) Guidance on subject major. It helps students to pay more attention to the study on professional basic courses and general education courses by guidance from all sides, to lay a good professional foundation, to understand the research direction, development and social needs of the subject, and guides the students to make a personalized training plan.

3) Guidance on scientific research innovation. We guide students to do scientific research, cultivate students' ability in scientific research and innovation, and guide students to participate in competition and innovative practice activities at various levels.

4) The guidance on employment and take part in the entrance exams for postgraduate schools. Students with academic potential are encouraged to take part in the entrance exams for postgraduate schools, and to continue their study. We should improve the guidance in terms of students career choice ideas, and help the students to get employment or start a business.

5) Mental health counseling. To Concern about students' amateur life and mental health, to guide students to arrange their study and life, and to help students develop good habits and enjoy study life at the University.

\section{Reference}

Chu Cai College, Hubei University. (2018, February 5th). College introduction. Retrieved from http://ccxy.hubu.edu.cn/xygk/xyjj.htm

Chu Cai College, Hubei University. (2018, February 5th). organizational structure. Retrieved from http://ccxy.hubu.edu.cn/xygk/jgsz.htm

Chu Cai College, Hubei University. (2018, February 5th). Zheng Diwei, a graduate, was invited to take part in the "senior as a leader" and to make a speech.Retrieved from http://ccxy.hubu.edu.cn/info/1006/3624.htm

Liu Jie \& Shen xi (2014). The exploration and practice of improving undergraduates' autonomous learning ability. The education of innovative talents, 1, 66-69.

Liu Pengzhi, Zhou Jianhua \& Zhang Jianas lin (2013). Research on Integrally Constructing the New Training Mode of Innovative Talents in Colleges and Schools and Its Practice. Educational research, 1, 58-64.

Qin Mingju (2015). Exploration and practice of the innovative talents cultivation in provincial colleges and Universities. Contemporary Continuing Education, 6, 76-78\&82.

Qiu Xueqing \& Li Zheng (2013). Innovating the sharing resources mechanism and building a cooperative 
education system in school. China higher education, 24, 23-25.

Zhu Yongkun (2016). From "cultural quality education" to "cultural education": the development of the comprehensive education concept in Colleges and Universities. Education Review, 3, 39-42.

\section{Copyrights}

Copyright for this article is retained by the author(s), with first publication rights granted to the journal.

This is an open-access article distributed under the terms and conditions of the Creative Commons Attribution license (http://creativecommons.org/licenses/by/4.0/). 